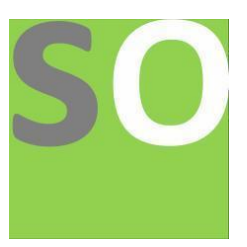

Article title: Modelling and Implementation of a Result Processing System

Authors: Oluwadamilare Ojo[1], Bernard a Akhigbe[2]

Affiliations: Computer Science and Engineering Department, Obafemi Awolowo University, lle-Ife Nigeria[1]

Orcid ids: 0000-0001-5587-1629[1]

Contact e-mail: lecturerdavid55@gmail.com

License information: This work has been published open access under Creative Commons Attribution License http://creativecommons.org/licenses/by/4.0/, which permits unrestricted use, distribution, and reproduction in any medium, provided the original work is properly cited. Conditions, terms of use and publishing policy can be found at https://www.scienceopen.com/.

Preprint statement: This article is a preprint and has not been peer-reviewed, under consideration and submitted to ScienceOpen Preprints for open peer review.

DOI: 10.14293/S2199-1006.1.SOR-.PPSUHH1.v1

Preprint first posted online: 25 August 2020

Keywords: Result processing system, Automation, Unified modeling language, Information systems, Software development life cycle, Object oriented programming, Implementation 


\title{
Modelling and Implementation of a Result Processing System
}

\author{
Ojo Oluwadamilare Femi* \\ Akhigbe Bernard Ijesunor \\ Department of Computer Science and Engineering, \\ Obafemi Awolowo University, Ile-Ife, Nigeria \\ *Corresponding Author: lecturerdavid55@gmail.com
}

\begin{abstract}
Result Processing System forms the key activities in the life span of a student. The demand for effective and efficient result computation and output presents the need to automate existing manual result processing system. The digitized process provides capabilities such as a centralized repository for storage, management and dissemination of result information to those concerned. A requirement gathering exercise based on the assessment of the existing manual process reveals that it is inefficient and rigorous in nature. The manual activities of the existing system were identified and modeled with the UML object-oriented methodology. Soft technologies such as the hypertext preprocessor - a high level scripting programming language and MYSQL database management systems were combined in the implementation of the student result processing system. The designed and implemented system was able to provide a robust database that generates various reports that are relevant to secondary schools. The reports included results' summary, results' broadsheet, students' result sheet, and so on. These reports are all downloadable because the system is able to generate them in PDF format. The system is unique in that it can be adopted and adapted to suit the result processing idiosyncrasies of any public secondary school.
\end{abstract}

Keywords: Result processing system, automation, unified modeling language, information system, software development life cycle, object oriented programming. 


\section{Introduction}

The result of any student remain basic criteria to show the capability of students anywhere in the world. Such results depict the academic potentials of students [1]. At basic school level, where students are trained and prepared to be able to take up more serious academic responsibilities at higher level the way and manners their result is processed therefore becomes important. This is because the result, which builds up from an earlier stage to a final stage when it serves as the means to certify if a student deserves to make progress must not be fraught with any ambiguities. This also implies that the lack of an adequate student result processing system must not be entertained, else the aim, which the result is produced for may not be met. An effective, efficient and error free student result processing system is thus required for proper result processing [2].

It is interesting to note that most authorities that manages elementary schools feels that the use of the Computer for school administration is only suitable for the production of letters, memos and other desktop related applications. Whereas the use of computers in schools cannot be over emphasized. Among many others tasks, it can help in administering the procedures of admission, the process of examination, registration after the process of admission, the scheduling of staff duties, and the storing of officials and students' records. These administrators are oblivious of the rich potentials of the Computer System. The practice, which is common place with respect to results processing is the manual preparation of statement of results, results' broadsheet and results summary [3]. Preparing these various information formats is usually tedious. The time spent on manually recording student results could have been used for data entry if there was a Computer System that is available and up and running. The absence of this has led to the waste of several man hour, which would have been deployed for others things. Secondly, after the manual result compilation, to check the performance of any student in all the various subjects the student is offering takes several other man hour because the teacher in charge would need to check name by name, class subject buy subject, and grades by grades. This long time of search from the student information record book can be avoided. Even the possibility of misplacing a student's record and the vulnerability of a student record being accessed by unauthorized persons [1] can be avoided with the use of modern information and technology tools.

The aim of this paper is to model the process of processing and managing students' result so as to mitigate the challenges with the rigorous steps that exist in the existing manual method. The specific objectives of the paper are to; present possible designs of a case study result processing system, possible implementation of the models from the designs presented, and test the developed result processing system. The rest of the paper is structured as follows; 2.0 provides a brief discourse on the motivation for the paper vis-à-vis a review of literature; and the summary of methodology and resultant design for the intended result processing system 
is found in section 3.0. The result processing system implementation based on the models designed and the papers' conclusion are found in section 4.0 and 5.0 respectively.

\section{Literature Review}

This section is made up of two sub-sections; the section that discourses the case study secondary school that is used in the paper and from where requirement gathering was done, and the second section contain the review of literature as a further motivation for the paper.

\subsection{The case study secondary school}

Requirement Gathering (RG) was fulfilled and carried out at some public state secondary schools in Ekiti, state. During the RG phase and school visit the types of assessment strategies that are employed were identified. They include students' assignments, agricultural science practical on school farms, other science practical, two or three periodic tests and the final examination. In a class situation a teacher is saddled with the responsibility of compiling up to 50 students' results with lots of stress on the class teacher. Some of the tedious activities a teacher must carry out along with the compilation is the manual calculation (e.g. addition and division) of each student's test, assignments (practical scores if a student is a science-based student) and exam scores. For every student, the teacher must add scores for the components just itemized. The teacher would also need to compute an average score for each student. This implies the addition of all the total scores of each subject that each student offered and the result of such addition is divided by the total number of subjects offered by each student. The next step in the computation process is to order the average scores of the students to be able to rank and sort each student's position in a class. This may look quite simple; but the teacher will also need to enter the result into the record "Report Sheet" of each student and then also create a "broadsheet called the Master Sheet or master mark sheet. This is the sheet that contain the total scores of all subjects offered by students, and the class average of all students with respect to the total numbers of subject offered in such class are shown for all the students for future records purposes. No doubt, this is stressful and time consuming and distracting because the teacher would not be able to attend to the other needs of the students during the period of the computational and recording exercise. These days most schools do have valedictory sessions at the end of a school year, where their final year students are given awards and sundry recognitions. The tasks of knowing who to give what and for what reason is also an issue that is struggled with year in year out.

Interestingly, all the various tasks that were identified earlier can be given computational interpretation and taking over by the computer. Teachers and school administrators can use the computer and stay off the stress of manually processing their results. This can even happen from a central location where the school administration can monitor the processes to ensure transparency. The level of transparency that is in tandem with student's result as a critical component for admission into the right discipline at higher level can be achieved with an effective result processing system [4]. The Table 1 below contains a summary of the major 
challenges the existing system of processing students' results in public secondary schools is grappling with.

Table I: Challenges of the case study existing student result processing system

\begin{tabular}{|c|c|}
\hline Challenges & Conception \\
\hline $\begin{array}{l}\text { Poor Security of } \\
\text { Documents }\end{array}$ & $\begin{array}{l}\text { Printed documents would often and always get lost at each } \\
\text { point in time. Some of the documents may even be destroyed } \\
\text { external elements such as termites and other insects. } \\
\text { Intruders can have excess to the manual files and that may } \\
\text { be the end of the documents. }\end{array}$ \\
\hline $\begin{array}{l}\text { Untimely Processing of } \\
\text { Results }\end{array}$ & $\begin{array}{l}\text { The time available to process results makes the job tough for } \\
\text { teachers. The time is always short. It often starts from the } \\
\text { end of a school examination till the day of vacation. This } \\
\text { means that teachers would work round the clock to ensure } \\
\text { the results are ready. }\end{array}$ \\
\hline $\begin{array}{l}\text { Production of Inaccurate } \\
\text { Results }\end{array}$ & $\begin{array}{l}\text { Human errors dues to human fatigue are sometimes made. } \\
\text { Therefore, teachers may often make mistakes when } \\
\text { calculating the total scores of each student in a particular } \\
\text { subject. They may get the average scores and grades of a } \\
\text { student's result wrong, and inaccurate results will be } \\
\text { released. }\end{array}$ \\
\hline
\end{tabular}

\subsection{Brief literature review}

Several efforts have been made to alleviate the burden of result computation that is usually borne by examination officers (in this case teachers) in the Nigeria clime. [2] observed that when results are processed manually, it may lead to the problem of computational error, insecurity of results, untidy results after changes must have been effected and excess work load on the examination officers and so on. For these reasons an effective, efficient and error free results processing system is required for proper result processing. Furthermore, designing and implementing an integrated software for result processing could minimize these problems. Password was used to grant access to only authorized user(s). Corrections or changes are effected without making the work untidy. Also stress on examination officers and computer operators will be greatly reduced. [5] Examined the inadequacies involved in the manual method of calculating Students results and proposes a solution by developing a software application to facilitate the automated processing of the results. The software was developed 
using Hypertext preprocessor (PHP) scripting language and employing MySQL Relational Database Management System in designing the database. The developed software was tested and work as expected. With the use of computers for information processing, the following are possible: instant access to students' personal and subjects' information, instant student information updating, automatic computation of students' results, storing students and subject information such as student's bio data, subject identity, subject name, and scores for the purpose of result computation, and producing user friendly data entry screens for ease of use [6].

Lastly, the inadequacies involved in the manual method of compiling students' result in secondary schools in Nigeria. The problems with the manual result processing were identified and a new system was proposed, designed, and implemented. In this work, a computer software application was developed to automate the processing of the results. The software was developed using PHP programming language and MySQL (My Structural Query Language), a relational database management system in designing the database; tested and found to have produced the expected results [1]. Different Programming Languages, Programming packages and Database management systems can be used to develop result processing software for computing students' results. PHP was used to communicate with and manipulate the database. Adobe Dreamweaver, an Integrated Development Environment, is used to create the Graphic User Interface and to write the codes. MySQL Server, a Relational Database Management System, is used to create the database tables and data. This application, though tested and found to be working as expected, has however not been put to use widely [7]. Java is a programming language used to build programs that can work on stand-alone computers and on the internet, its primary features are object-oriented and a cross platform language. By cross platform, it means that the programs can run across several platforms such as Microsoft Windows, Apple Macintosh, and Linux. MySQL, a Relational Database Management System (RDBMS) is used to create database tables and data. MySQL is very fast, reliable, and easy to use, and its connectivity, speed, and security make it highly suited for accessing databases [8]. Moreover, there are undoubtedly several other similar Programming Language and Database management systems in existence. Some previous work has actually been carried out using several of such programming languages and packages which prove to be working fine in this area. There is, however, always room for improvement. This new application is intended to have reduced complexity and greater ease of use, in order to enhance maintainability while still retaining good speed and accuracy.

Information systems used to manage student data have been referred to in various ways: Student Information Systems (SIS), Student Management Information Systems (SMIS), Student Data Systems (SDS), Student Data Warehouse (SDW), Student Academic Information Systems (SAIS), or Student Information Management Systems (SIMS), [9]. [10] Encapsulates the essence of a student information system. He defines SMIS as "an integrated 
software package that maintains, supports, and provides inquiry, analysis, and communication tools that organize student accountability data into information to support the educational process". A result management system (RMS) is only an aspect of a complete SIS package. The United State Department of Education views student data systems as encompassing "hardware and software that provide many different functions to users, such as storing current and historical data, rapidly organizing and analyzing data, and developing presentation formats or reporting interfaces". My aim is to design and implement a Public Secondary Schools RMS, this system will have the capability of storing current and historical data, organize and analyze this data as required and the software will have the ability to be integrated with other SIS packages if the need arises. Due to the manual system, the desk officers both in Exams and in Records and Statistics who are in charge of result processing find it difficult to edit documented results and cancel out some errors such as omission or wrong entries. Even though these corrections are made, the paper work will look mutilated [11]. [2] Usually manual processing or manual mode of generating students 'results usually ends with correction of errors and when they are given out to students, they look untidy.

\section{Research Design and Methodology}

In this paper, the incremental development methodology was adopted. Interview method was used (to capture needed data and information from secondary schools visited in Ekiti state concerning the existing system) during the requirement engineering. Methodology refers to a set of procedures, techniques and technologies employed in developing any system. This chapter describes the methodology that is used in developing an e-result processing system. As the system under consideration is a software system, Software System Life Cycle (SSLC) is adopted to provide guidance needed towards a successful completion of a working system. This section covers the modeling and the design of the system using object-oriented methods. Software Development Life Cycle implementations are of various types such as Waterfall model, prototype model, agile mode, $\mathrm{v}$ model, incremental model and others. The model that best suits this project is incremental model; this is because incremental model allows the requirements to be divided into various builds. Each build consists of multiple development cycles, with each cycle divided into smaller, easily managed modules. In this model, each module passes through the requirements, design, implementation and testing phases. This model produces the working version of software after the first module with each subsequent release of module adding new features to the previous version. This model fits this project as the requirements of the complete real-time e-result processing system are well defined and understood, although small requirement evolves over time but the major requirements are well defined and because it can be used conveniently by one person developing a system. This model is good because it generates a working software quickly, it very flexible hence, its scope and requirements can be easily changed and it has low initial cost. 
Further, the design of the system was done using Unified Modeling Language (UML) tools such as use-case diagram, class diagram, activity diagram and sequence diagram. The front end design of the system was implemented using the following technologies HTML, JavaScript, CSS and Macromedia Dreamweaver 8 IDE (Integrated Development Environment) where the coding was done and the various data input forms, window and menu objects were created. The back end design of the system was implemented using the following technologies MySQLi (an example of RDBMS) relational database and PHP (Scripting programming Language) was used as a suitable programming language for the development of the system. Beta test has been used for testing the system. The diagram of incremental model is shown in Figure 1 below. Figure 2 which is the architecture of the system, architecture of any system describes its component and how they are connected together. The application in view is of three-tier client/server application. In the three-tier architecture, a middle tier is between the clients or users (teachers or parents/students), and or administrator environment and the server environment. For example, if you were trying to access a website with a three-tier architecture type, your computer (first tier) would connect to the website's database application (second tier). The database application would then send a request, on your behalf, to the main server (third tier). The main server would process your request and forward it back to the database application, which would then present the information to you. For this application, the tools used to develop the first tier are JavaScript, CSS, Html, JavaScript; tool for the second tier is PHP and the tool for the third tier is MySQL with respect to mysqli.

Although, most of the aforementioned cited literatures have captured great benefits of computerizing computation of students' results compared to the old manual method of doing so. But, it was observed that the design being used in their work was not enough (e.g. like the breaking down of the activity of the proposed system into a more enlightened format etc.) Most importantly, it was observed that this particular software that we are talking about has been put into use by the general populace. Thus, the needs for computerized system that is robust, fast, effective and efficient. 
Build 1

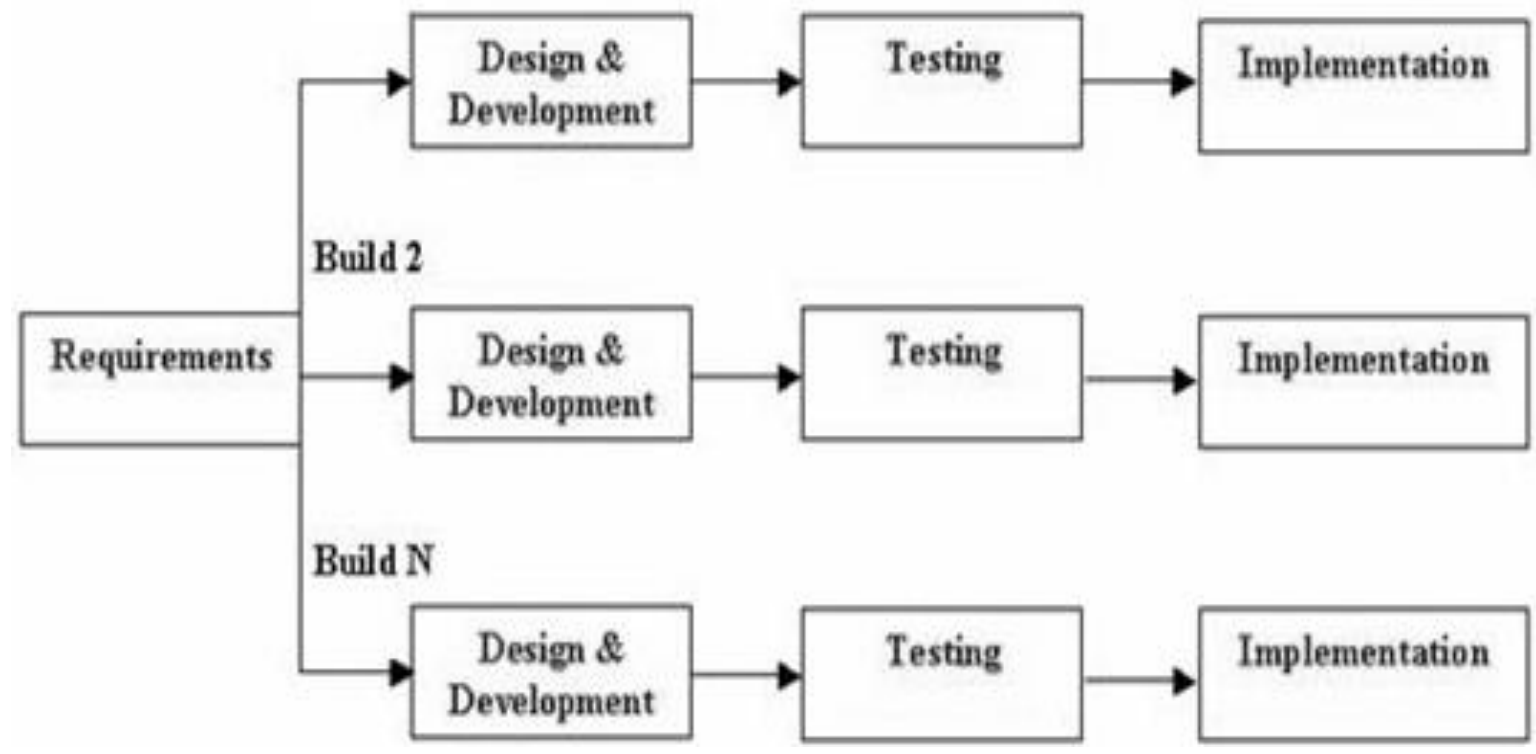

Figure 1. Incremental Life Cycle Model

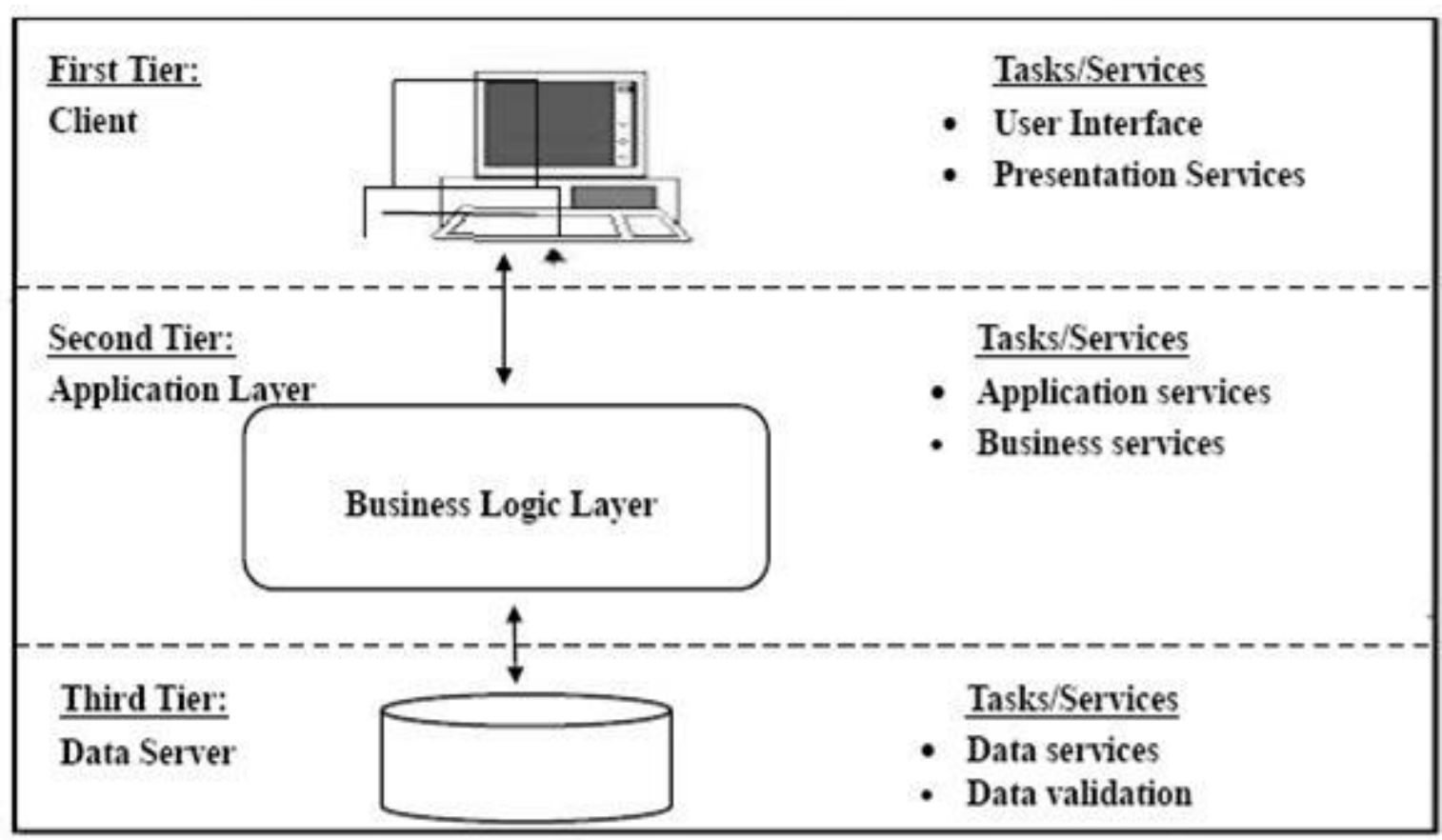

Figure 2. System (Three-Tier Client/Server) Architecture 


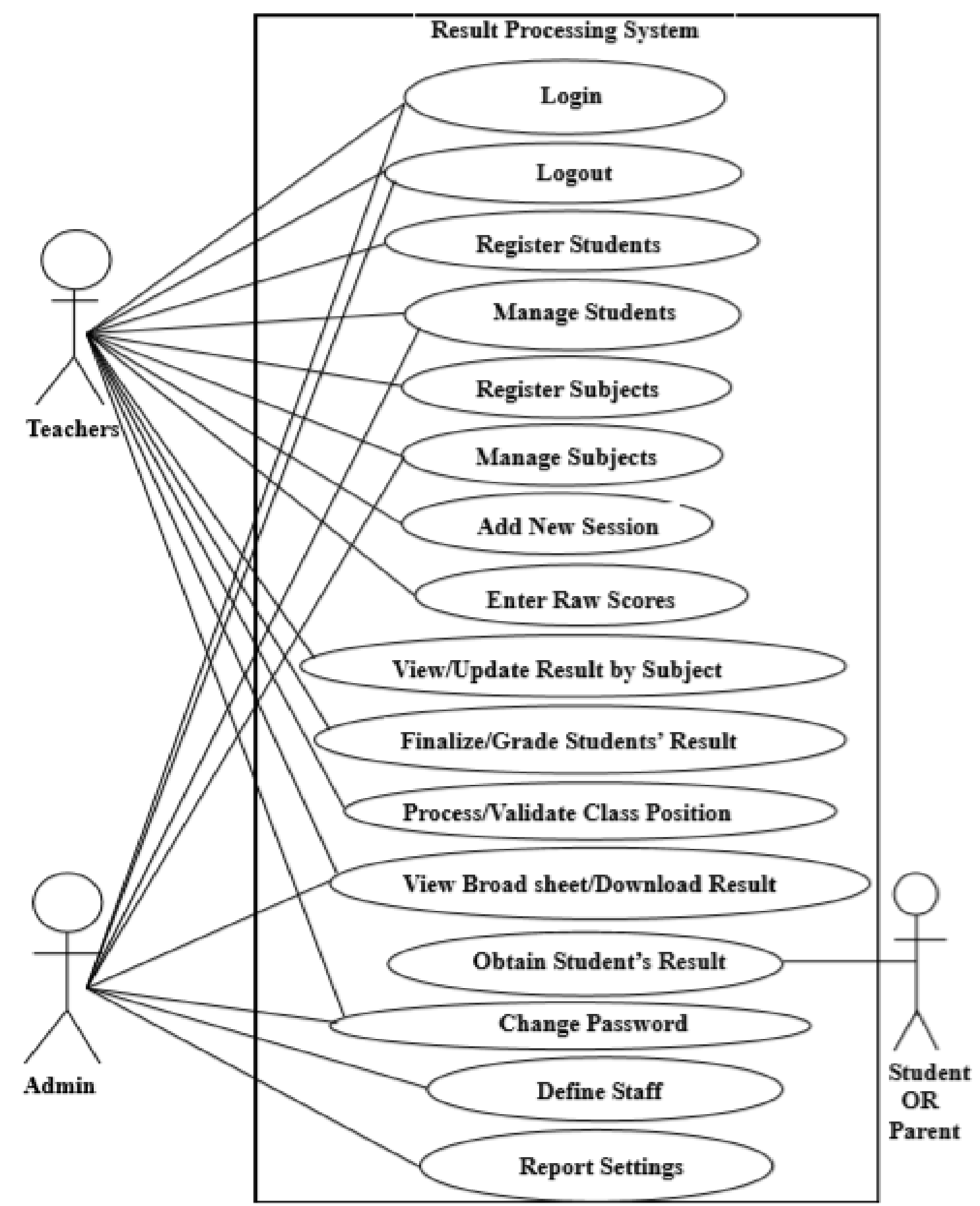

Figure 3. Use Case Diagram of the System

Activity diagram are an updated and enhanced data flow diagram. The activity diagram specified for the E-result processing system shows some activities that can be performed by an authentic or authorized users (teachers or staff and or parent) that has already been defined by then administrator (precisely, vice principal academic). The activity diagrams are shown in Figure 4 and Figure 5 respectively below. 


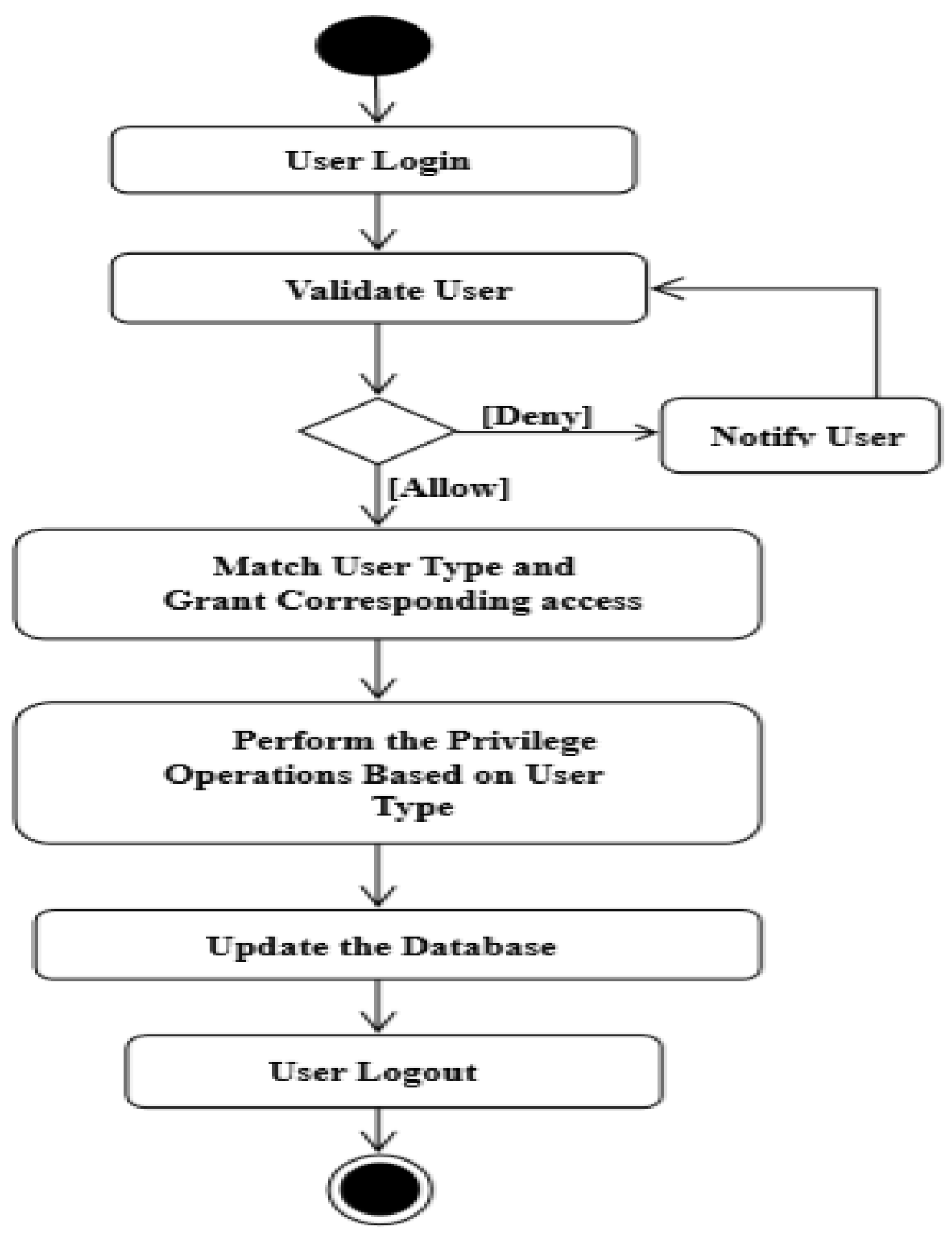

Figure 4. Activity Diagram of the System 


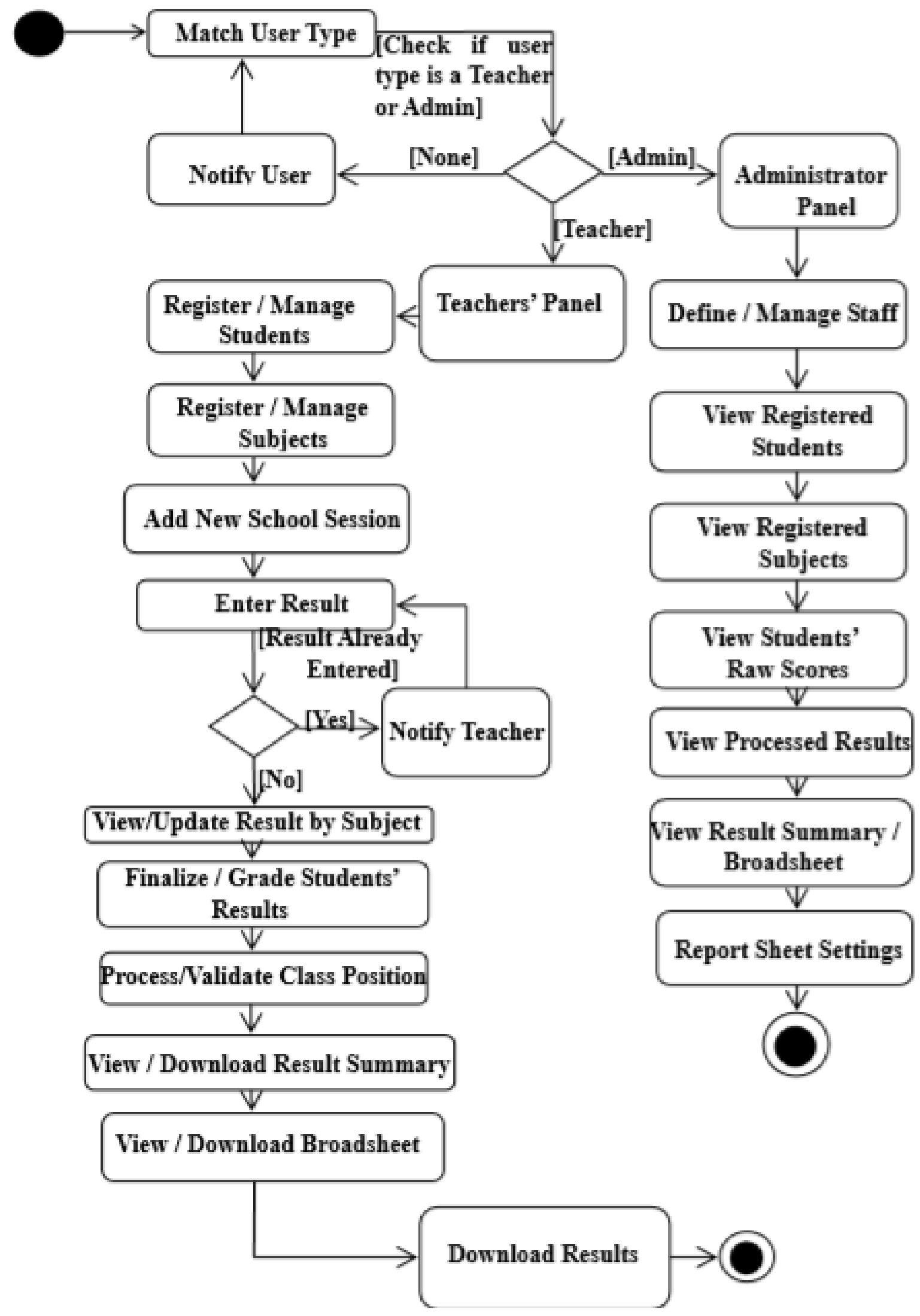

Figure 5. Activity Diagram of Operations 


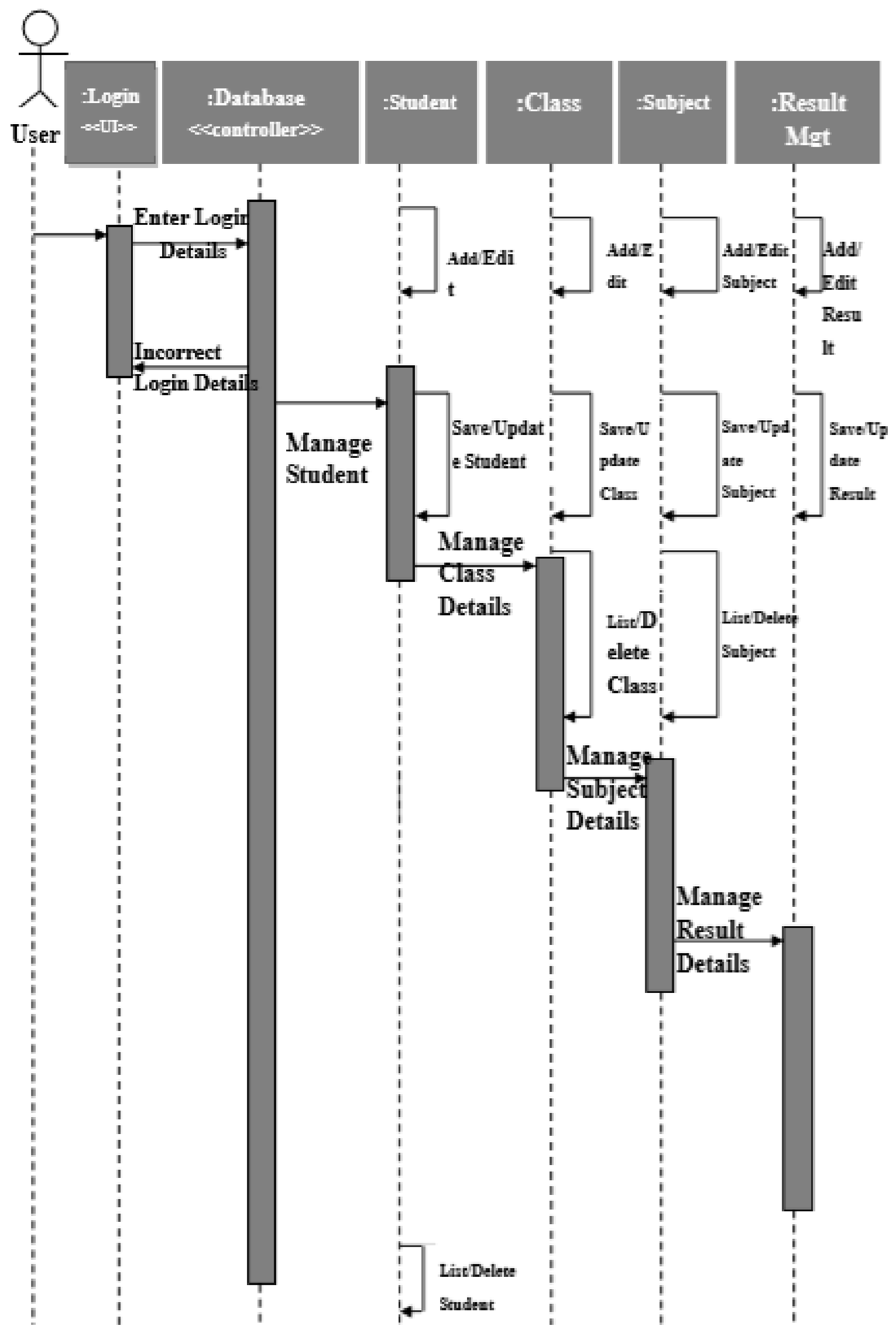

Figure 6. UML Sequence Diagram of the System 
Sequence diagram was used to depict the chronological-structured event flow through a use case, by creating a sequence diagram; the objects that participate in the use case are identified. Figure 6 represents the sequence diagram for the system. A class diagram is a type of static structure of entities in the system; a UML diagram that describes the structure of a system by showing the system's classes, their attributes, and the relationships between the classes. The diagram below shows all the classes, attributes and relationships between classes for this application. The Classes and the relationship among them are shown in the Figure 7. 


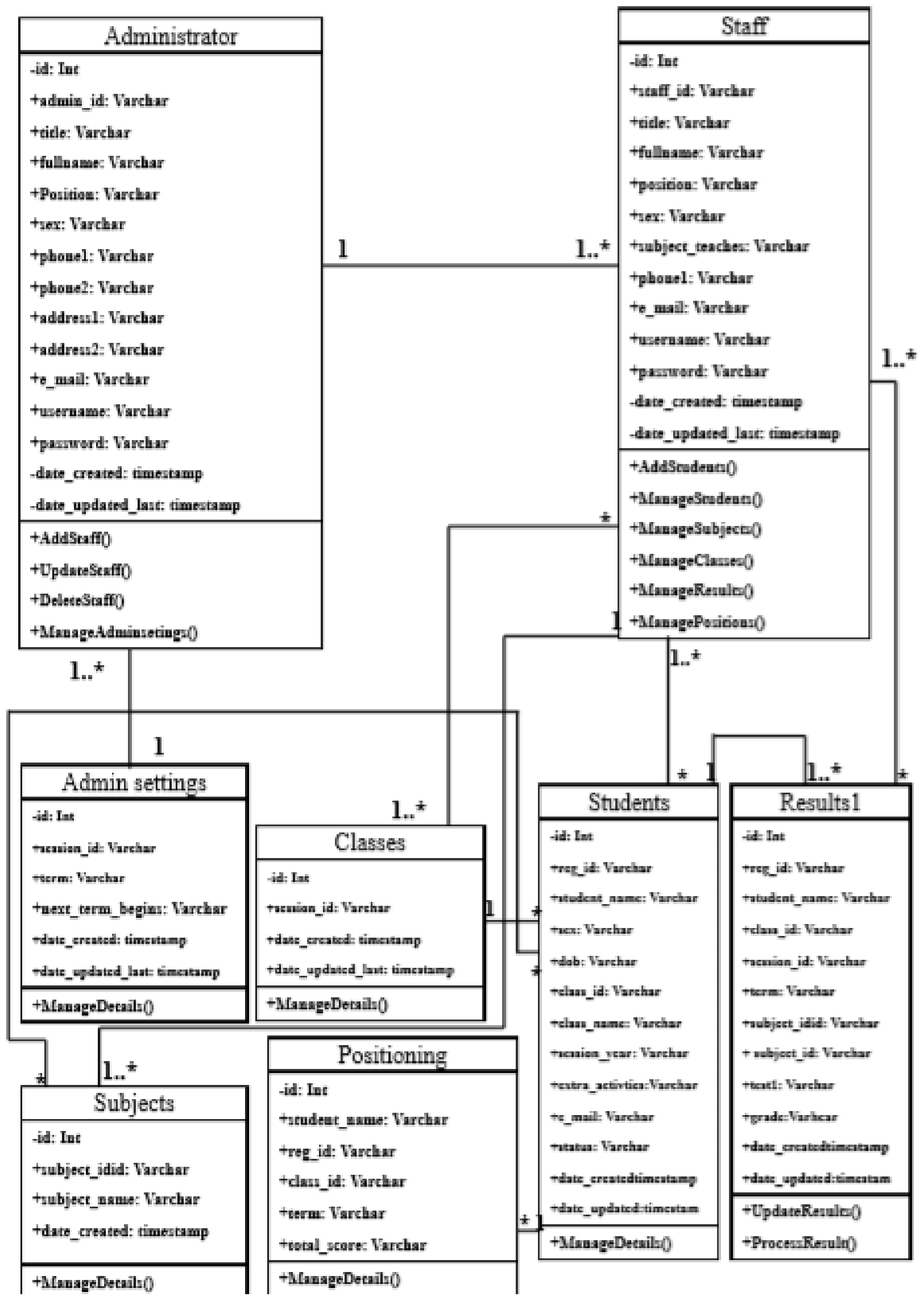

Figure 7. UML Class Diagram of the System 


\section{System Implementation and Testing}

This chapter presents the System implementation and testing which has to do with the conversion of the system's conceptual and logical designs into a physical implementation. Implementation activities include selection and installation of chosen language, coding, debugging and testing. In this project work, a WAMP server was installed on a system and the software was coded using an IDE of Macromedia Dreamweaver 8 and deployed on a localhost. The coding involves a systematic representation of the system's model in an automated form under a choice development environment. Debugging and testing the software include removing the errors of the system at the different stages of its development and running the system severally as each error is debugged. The software runs well on a local server following the architectural structure stipulated in the design.

\subsection{Development Environment}

The development environment used in this project work "Development of an E-Result Processing System for Public Secondary Schools" is HTML and MYSQL database. HTML was used to create the interfaces, the forms and the logins. It enables a formal presentation of the PHP code to the web and facilitates the creation of web-pages. MYSQL server is webbased database software that allows a multi-user access. The minimum attributes of a system required to run the package on a localhost are; Windows XP operating system, 100GB data space, 1GB memory space, Any of these browsers can run the system; Google Chrome (most preferred for this application), UC Browser, Opera, Mozilla Firefox, Internet Explorer and so on, Windows 7 or any higher Windows OS for systems running Windows Operating System.

\subsection{Choice of the Programming Language Used}

The choice of programming language used depends on the suitability of the language attributes to the scope and usage of the system developed. PHP is a scripting language. It facilitates the development of a web-based program and creation of web-pages. The WAMP server has some sets of scripts, logs, SQL manager and PHP code that enable communication between the MYSQL database and HTML. The system developed is an online system that allows multi usage. The WampServer enables data to be shared among users online and secures the data from the various users. The cascading style sheet (CSS) formats the presentation of a web page to the end-user. It creates a suitable and user friendly outlook for the user interface. These attributes informed the choice of the language used. JavaScript is a scripting language that is used mostly to build web applications. It can be used on both the front-end and the back-end of web application. On the front-end, it is used to access the API (Application Programming Interface) provided by the browser. One of the APIs is the DOM (Document Object Model) which allows developer to make a web page interactive by reacting to the events generated by user actions such as moving the mouse, clicking a button and other events. 


\subsection{Results and Discussion}

The results of this system include several graphical user interfaces (GUIs) through which users interact for purposes of which the system was developed. The GUIs of individual users varies from each other due to the variation in task to be performed by the users. The user interface of the system is the media with which the users of the system interact with the system without knowing / seeing the underlying functionalities of the system.

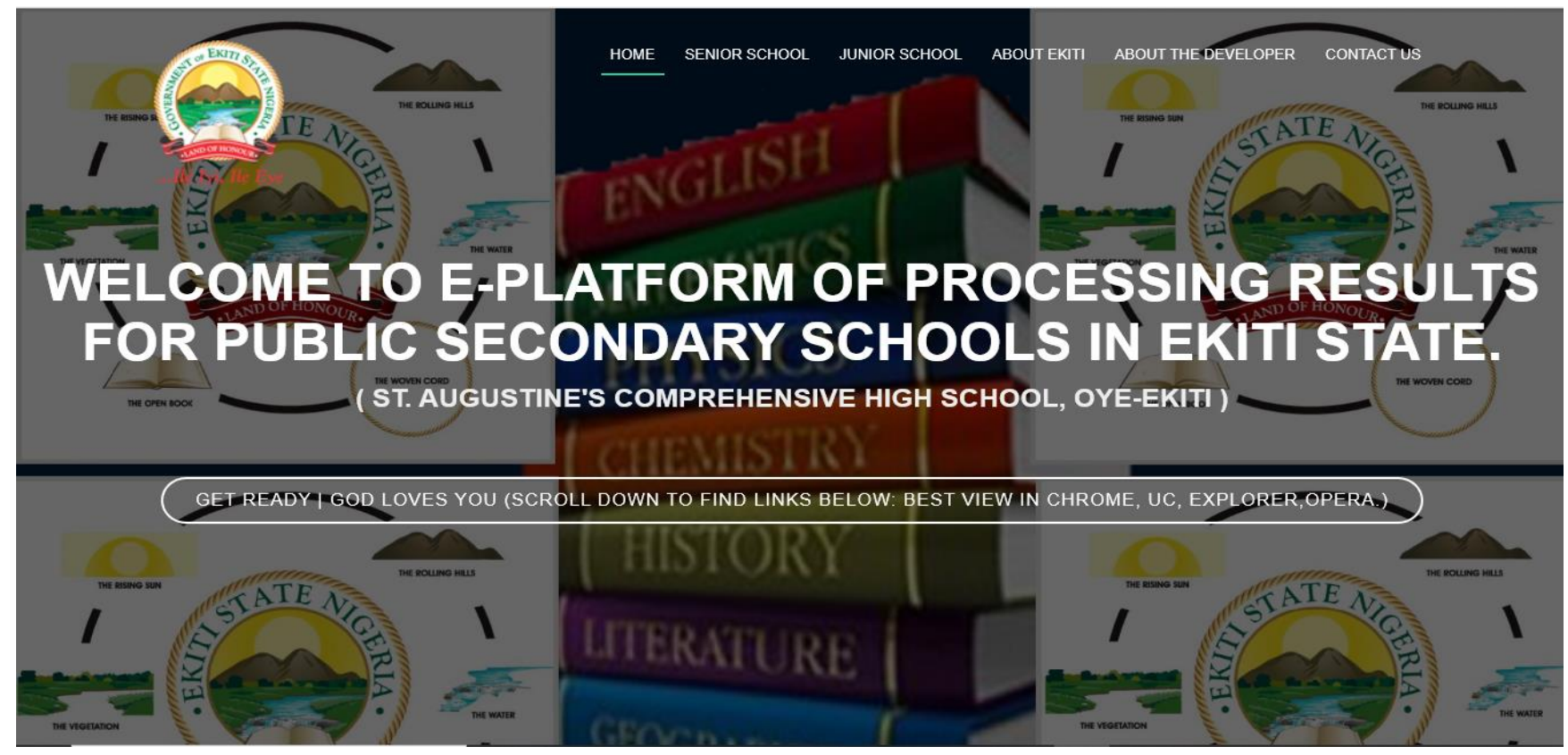

Figure 8. GUI for Home page

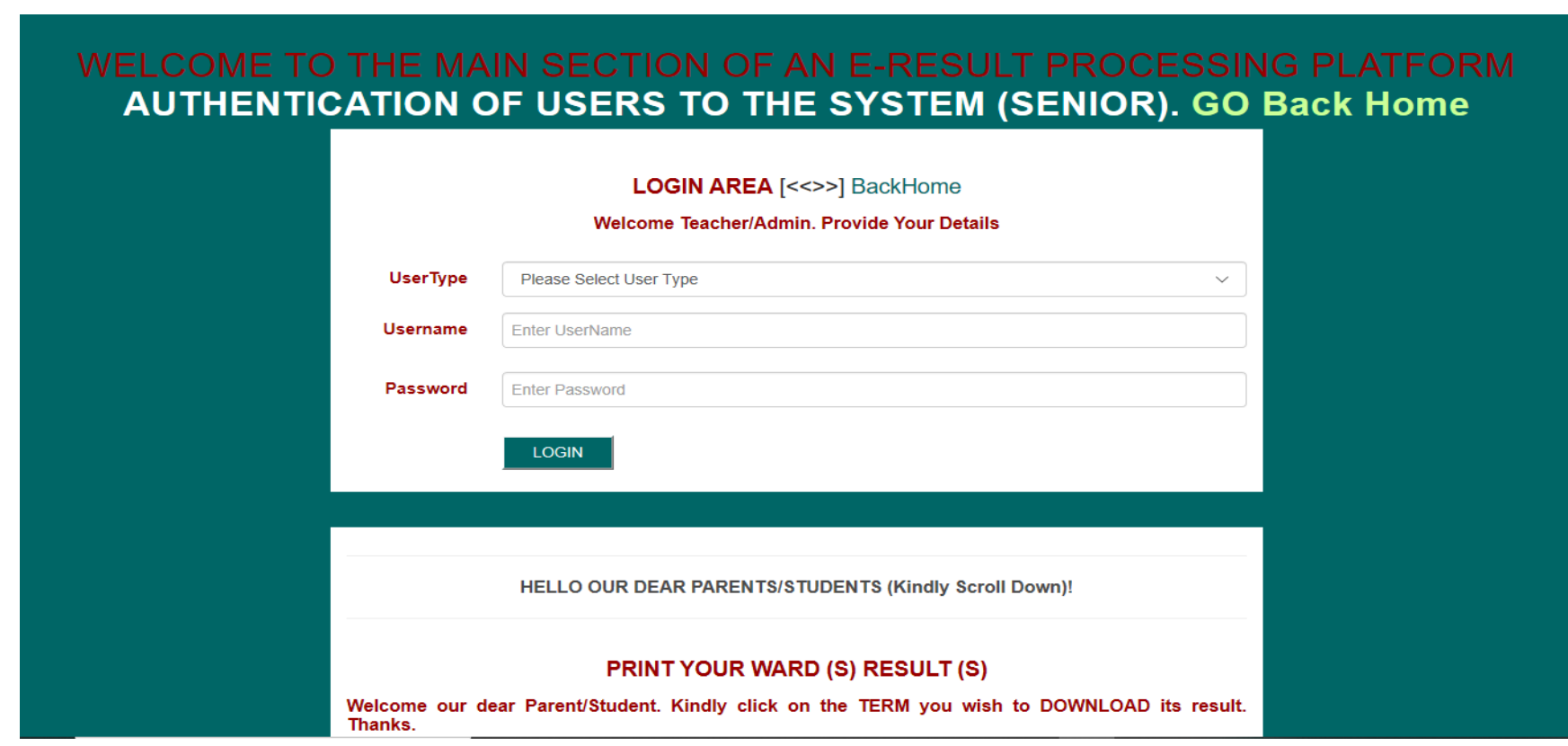

Figure 9. GUI for Login Page and Platform for Downloading Students' Result by Parents 


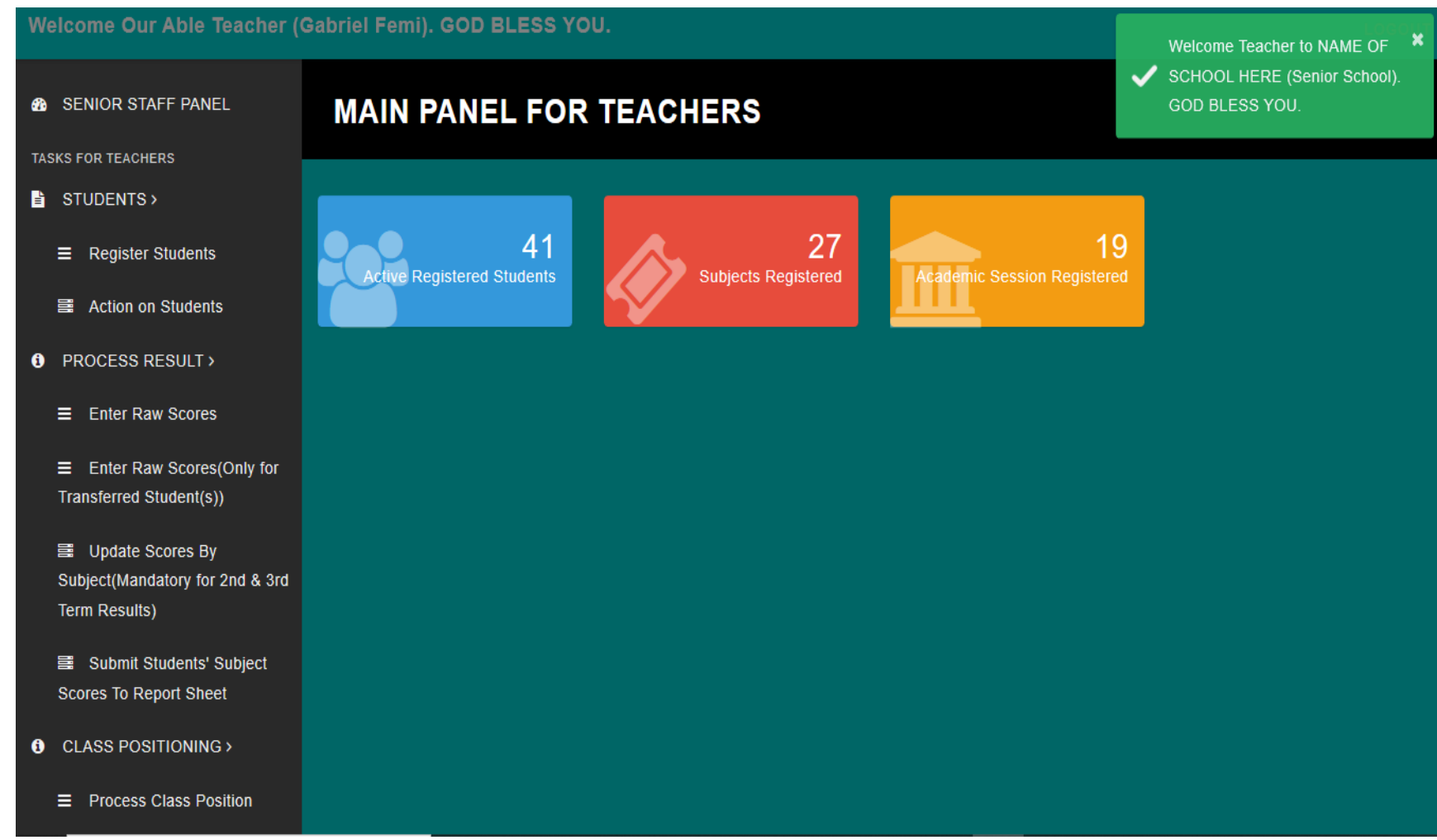

Figure 10. GUI Showing Main Panel for Teachers

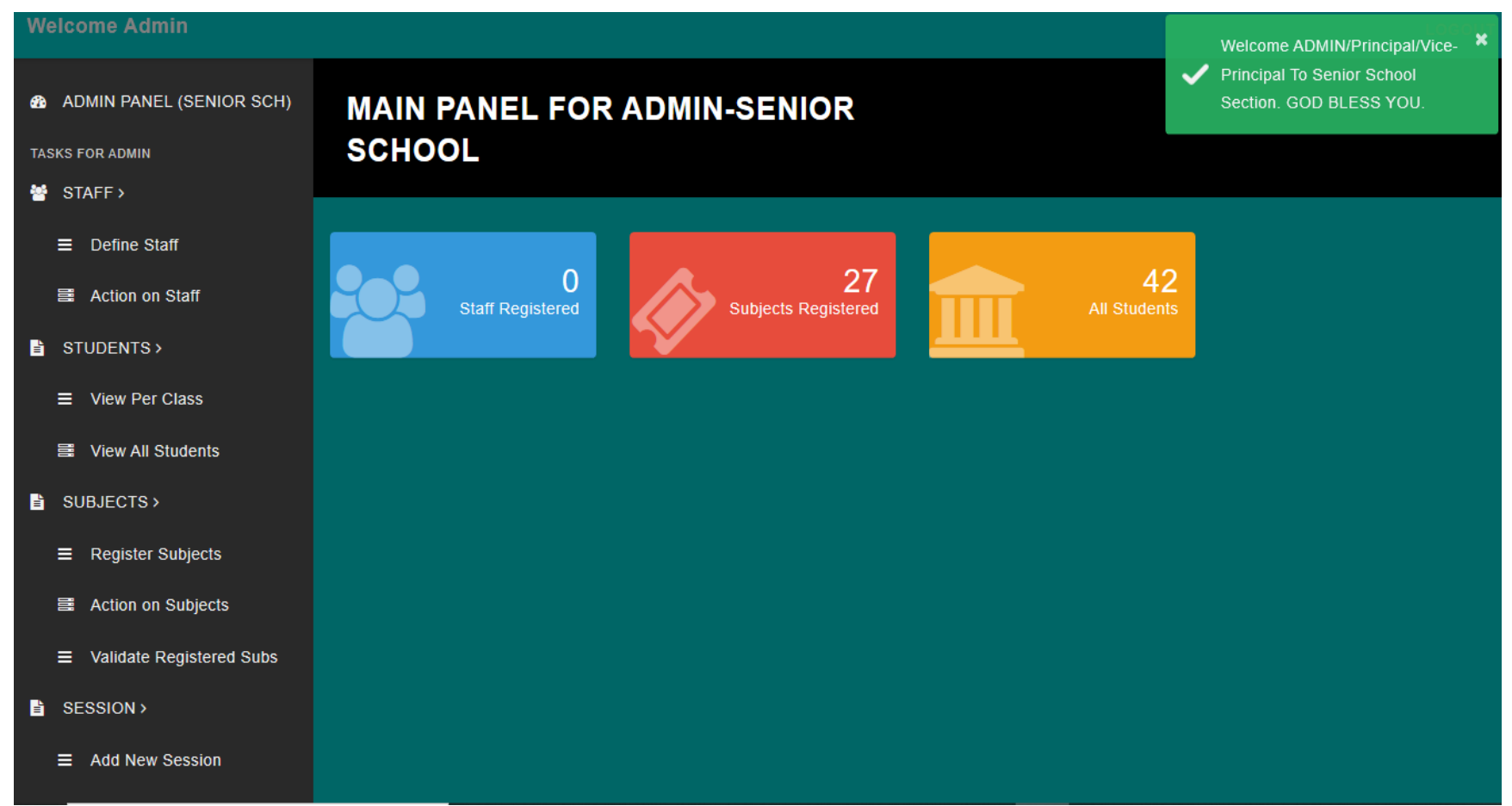

Figure 11. GUI Showing Main Admin Panel 


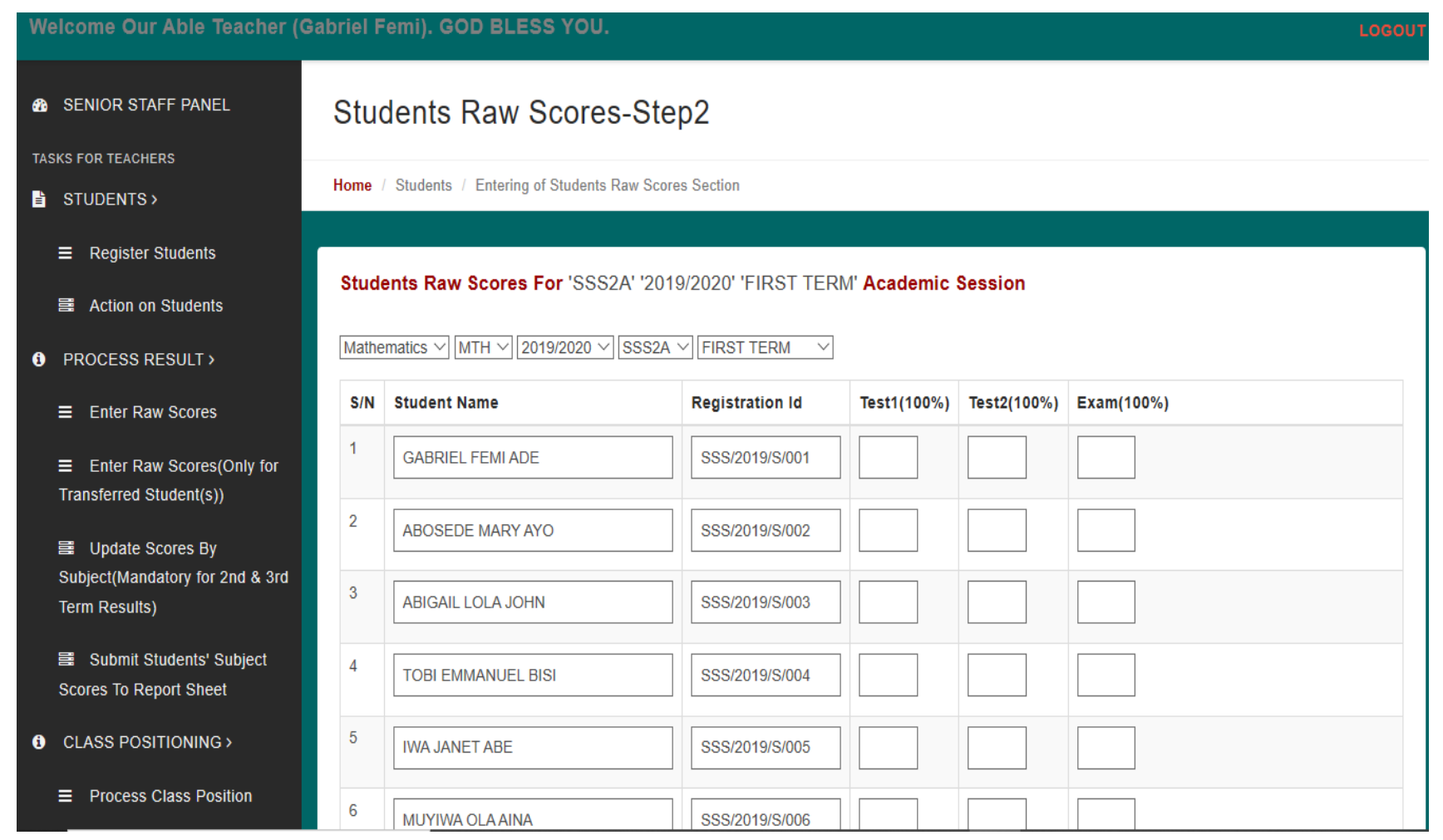

Figure 12. GUI Showing Page for Entering of Students' Raw Scores

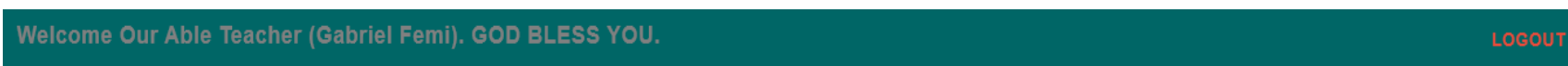

Validate Student Positions For First Term

Home / Students / Students Positions

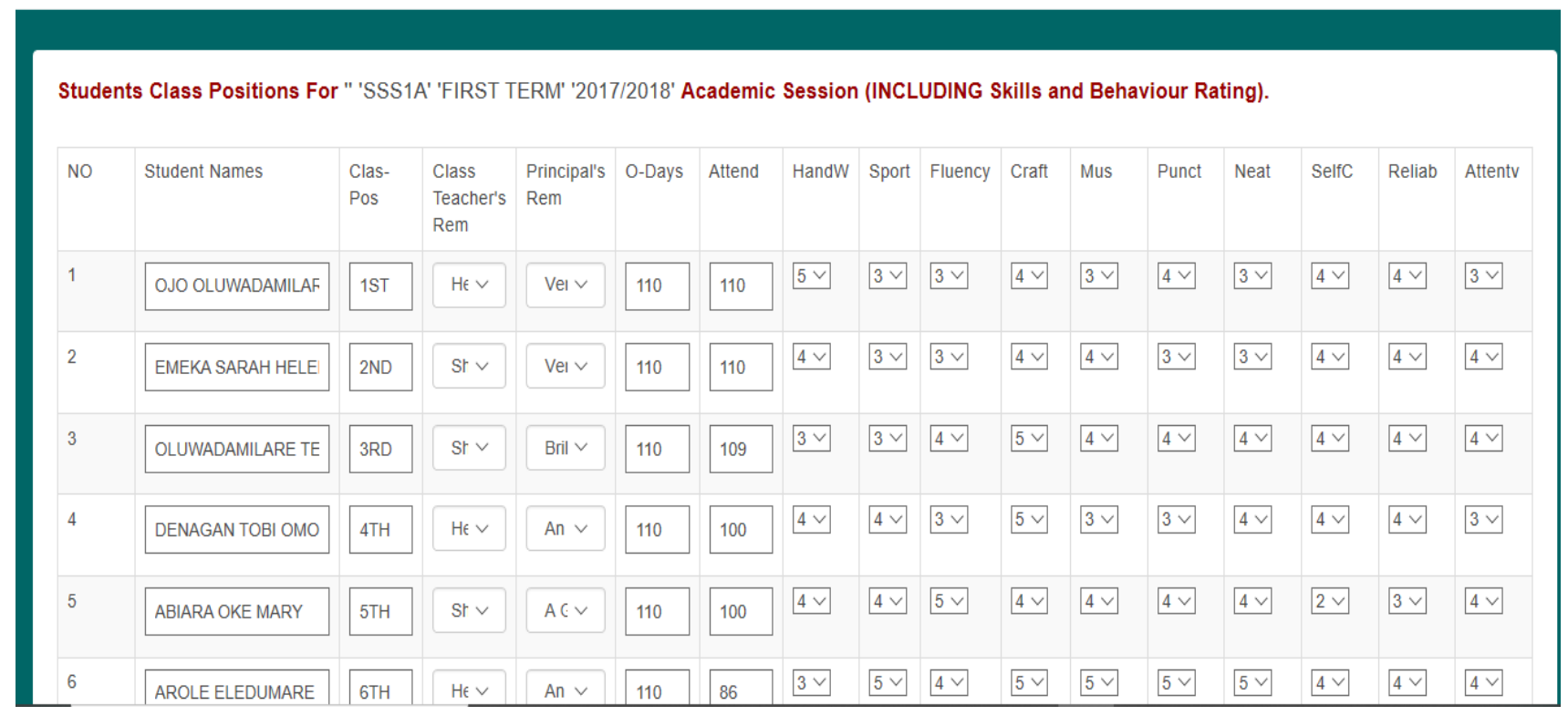

Figure 13. GUI Showing Page for Validation of Overall Class Positions, Class Teacher's and Principal's Remark including Skills and Behaviour Rating 
Results Broadsheet For FIRST TERM-SSS1A-2018/2019 Academic Session of NAME OF THE SCHOOL SHOULD APPEAR HERE

\section{FOLLOWED BY TOWN....}

\begin{tabular}{|c|c|c|c|c|c|c|c|c|c|c|c|}
\hline $\mathbf{S} / \mathbf{N}$ & Student Names & AGR & BIO & CHM & CIV & ENG & FMT & GEO & MTH & PHY & YOR \\
\hline$\overline{1}$ & ABIARA OKE MARY & 73 & 69 & 81 & $\overline{660}$ & 82 & 89 & 81 & 75 & $\overline{79}$ & 84 \\
\hline 2 & AKINTOYE Oluwatoromo & 60 & 51 & 80 & 59 & 59 & 88 & 84 & 82 & 22 & 21 \\
\hline 3 & AROLE ELEDUMARE IDOWU & 59 & 51 & 87 & 60 & 69 & 88 & 71 & 86 & 94 & 85 \\
\hline 4 & BABATUNDE AINA BOLA & 71 & 48 & 84 & 60 & 80 & 85 & 82 & 76 & 82 & 73 \\
\hline 5 & BAMISILE Oluwatosin & 62 & 74 & 69 & 79 & 83 & 86 & 82 & 83 & 92 & 82 \\
\hline 6 & DENAGAN TOBI OMOOLORUN & 58 & 62 & 83 & 59 & 59 & 88 & 60 & 78 & 64 & 74 \\
\hline 7 & KEHINDE ALABA ESTHER & 79 & 73 & 84 & 69 & 69 & 73 & 92 & 100 & 85 & 69 \\
\hline 8 & OGUNGBE IMOLE FAITH & 83 & 83 & 86 & 73 & 86 & 77 & 79 & 88 & 72 & 87 \\
\hline 9 & OJO OLUWADAMILARE FEMI DAVID & 69 & 96 & 82 & 75 & 71 & 97 & 97 & 89 & 80 & 88 \\
\hline 10 & OLUSANYA FAITH MARY & 60 & 63 & 77 & 78 & 83 & 74 & 76 & 93 & 70 & 67 \\
\hline \multicolumn{2}{|c|}{ CLASS AVERAGE } & 67 & 67 & 81 & 67 & 74 & 85 & $\mathbf{8 0}$ & 85 & 74 & 73 \\
\hline
\end{tabular}

Principal's Stamp \& Signature

GOD BLESS OUR TEACHERS

Figure 14. GUI Showing a Particular Class Result Broadsheet for a Particular Academic Session and Term

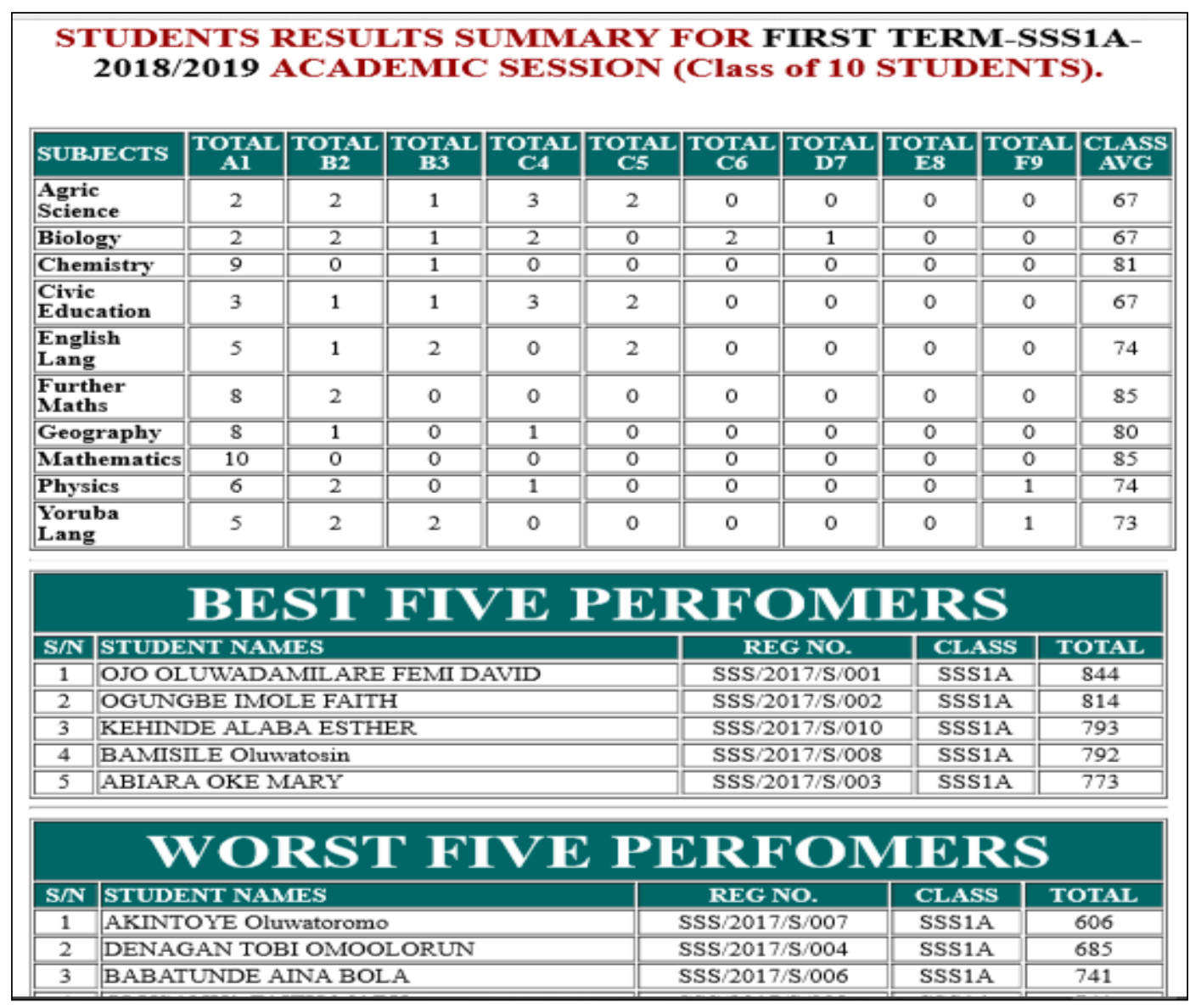

Figure 15. GUI Showing a Particular Class Result Summary for a Particular Academic Session and Term 


\begin{tabular}{|c|c|c|c|c|c|c|c|c|c|c|c|c|c|}
\hline \multicolumn{14}{|c|}{$\begin{array}{l}\text { CONTINUOUS ASSESSMIENT DOSSIER FOR SENTOR SECONDARY SCHOOL } \\
\text { REPORT SHEET FOR: THIRD TERM 2017/2018 ACADEMIC SE S SION } \\
\text { NAME: ONO OLUWADAMILARE FEMI DAVD CLASS: SSS1A } \\
\text { ADMIISSION NO: SSS2017/ SO001 SEX: Male } \\
\text { POSITION IN CLASS: 1ST OUT OF } 7 \text { STUDENTS }\end{array}$} \\
\hline \multicolumn{14}{|c|}{ BREAKDOWN OF STUDENT'S PERPORMANCE IN ALL THE SUEJECTS OFFERED } \\
\hline \multirow{2}{*}{ SUBJECTS } & (a) & (b) & (c) & (d) & (e) & (i) & (g) & (b) & (i) & (j) & (k) & (I) & (m) \\
\hline & PT196 & PT29 & $(\mathbf{a}+\mathbf{b}) / 2$ & EOTE 96 & $(c+d) / 2$ & LTC & $\operatorname{CUM}(\mathrm{e}+1) / 2$ & $\operatorname{Max}$ & Min I & POS & Grade & ClassAvE & Remark \\
\hline \begin{tabular}{|l|} 
Agric \\
Science \\
\end{tabular} & 90 & 77 & 84 & 69 & 77 & 78 & 78 & 78 & 21 & |lst & Al & 39 & Distinction \\
\hline Biology & 88 & 100 & 94 & 100 & 97 & 89 & 93 & 93 & 25 & $1 s t$ & A1 & 58 & Distinction \\
\hline Chemistry & 32 & 45 & 39 & 67 & $\overline{253}$ & 60 & 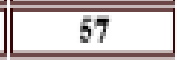 & 61 & 28 & 3rd & $\mathrm{C} 5$ & 44 & Credit \\
\hline Economics & 75 & 68 & 72 & 88 & 80 & \begin{tabular}{|l|}
87 \\
\end{tabular} & 84 & 84 & 17 & $1 s t$ & A1 & 46 & Distinction \\
\hline \begin{tabular}{|l} 
English \\
Lang \\
\end{tabular} & 67 & 78 & 73 & 80 & 77 & $\mid 71$ & 74 & 74 & 36 & 1st & B2 & 52 & V.Good \\
\hline $\begin{array}{l}\text { Further } \\
\text { Maths }\end{array}$ & 70 & 75 & 73 & 90 & 82 & 72 & 77 & 77 & 32 & 1st & Al & 46 & Distinction \\
\hline Geography & 86 & 80 & 83 & 88 & 86 & 76 & 81 & 81 & 36 & 1st & A1 & 52 & Distinction \\
\hline Mathematics & 76 & 87 & 82 & 97 & 90 & 88 & 89 & 89 & 37 & 1st & Al & 54 & Distinction \\
\hline Physics & 60 & 50 & 55 & 77 & 66 & 69 & 68 & 68 & 34 & 1st & B3 & 48 & Good \\
\hline Yoruba & 80 & 60 & 70 & 77 & 74 & 73 & 74 & 74 & 20 & $1 s t$ & B2 & 42 & V.Good \\
\hline \multicolumn{14}{|c|}{ 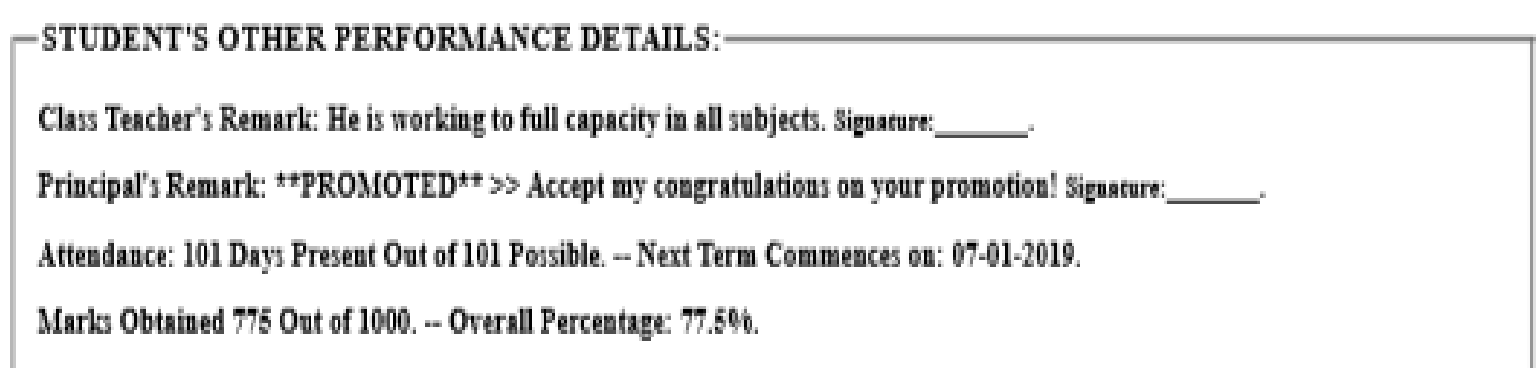 } \\
\hline \multicolumn{11}{|c|}{ 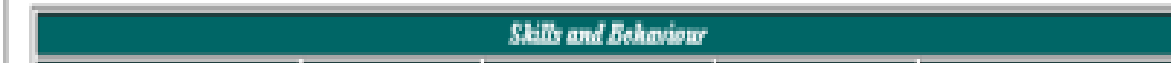 } & \multicolumn{3}{|c|}{ Egys To Refingy } \\
\hline \multicolumn{2}{|c|}{$\frac{\text { Hand Writing }}{5}$} & \multicolumn{2}{|c|}{ Sports } & \multicolumn{2}{|c|}{ Fluency } & \multicolumn{2}{|r|}{ Crafn } & \multicolumn{3}{|c|}{ Musle } & \multicolumn{3}{|c|}{ 5: Excellent" } \\
\hline & \multirow{2}{*}{\multicolumn{2}{|c|}{$\begin{array}{c}5 \\
\text { Neatness }\end{array}$}} & \multicolumn{2}{|l|}{4} & \multicolumn{2}{|r|}{4} & \multicolumn{3}{|c|}{2} & \multicolumn{3}{|c|}{ 4: Vory Good ${ }^{*}$} \\
\hline \multicolumn{2}{|c|}{ Punctuality } & & & \multicolumn{2}{|c|}{ SelfCentrol } & \multicolumn{2}{|c|}{ Rellability } & \multicolumn{3}{|c|}{ Attentiveness } & \multicolumn{2}{|c|}{31 Good $^{\circ}$} & \\
\hline \multicolumn{2}{|l|}{4} & & 3 & \multicolumn{2}{|c|}{5} & & 5 & \multicolumn{3}{|c|}{5} & \multicolumn{2}{|c|}{2 \& 1:Fair / $/$ Pent $^{+}$} & \\
\hline
\end{tabular}

Figure 16. GUI Showing the PDF Format of the Downloaded Result for a Particular Student, Class, Session and Term 


\subsection{System Testing}

The testing of the system was done in two phases: alpha testing and beta testing to ensure the system developed meet its requirement specification. In the first phase, alpha testing was carried out, this involved the developer checking for errors in the operation of the system and fixing it. The beta testing involved engaging some of the users in testing the functionalities of the system. The testing of the system using some metrics is summarized in Table 1 below.

Table 1. Showing Result of the System Testing

\begin{tabular}{|c|c|c|c|c|c|}
\hline $\mathrm{S} / \mathrm{N}$ & Metrics & $\begin{array}{l}\text { Very Good } \\
(75-100) \%\end{array}$ & $\begin{array}{c}\text { Good } \\
(50-75) \%\end{array}$ & $\begin{array}{c}\text { Fair } \\
(25-50) \%\end{array}$ & $\begin{array}{c}\text { Poor } \\
(0-25) \%\end{array}$ \\
\hline 1 & Ease of Use & & Yes & & \\
\hline 2 & User Friendliness & & Yes & & \\
\hline 3 & Responsiveness & Yes & & & \\
\hline 4 & Error Free & Yes & & & \\
\hline
\end{tabular}

\section{Conclusion and Recommendation}

In conclusion, this Paper presents a software application that is capable of storing and processing students' results at the click of the button and presenting the output in a certain required forms. Its qualities include enabling error free registration, reduction in the cost and time spent in computing Students' results, faster generation of a term result per class and enabling the teachers and or administrators to view every term result of a whole class in a single sheet called the broadsheet as well as the result summary for a whole class, The Application is easy to use, reasonably secure and enforces data integrity resulting from the use of a relational database management system.

The software design if effectively implemented will solve the problems associated with manual processing of students' results in public secondary schools by putting in place an efficient computerized result processing system. It is recommended for application in public secondary schools in Ekiti State which experience difficulties with the computation of students' results. This software is subject to change and very much essential for other public secondary schools from other states in Nigeria to embrace it and implement it into their own system. 


\section{References}

[1] Ezenma, A. A., Emmanuel, B., and Choji, D. N. (2014). Design and Implementation of Result Processing System for Public Secondary Schools in Nigeria. International Journal of Computer and Information Technology. Vol. 3, No. 1 Internet: <www.jatit.org>. Accessed on 02/06/2018.

[2] Grey, S. (2010). "Mode of processing result System", Himachal Pradesh University Journal. Pp 127-134.

[3] Dada, O. M., Raji, A. K., and Oyedepo, F. S. (2017). Design and Implementation of an Integrated Result Processing System in a Networked Environment. Biomedical Statistics and Informatics. Vol. 2, No. 5, pp. 131-137.

[4] Beka, A. P. and Beka, F. T. (2015). "Automated result processing system: A Case study of Nigerian University," International Journal for Research in Emerging Science and Technology, Vol. 2.

[5] Emmanuel, B. and Choji, D.N. (2012). "A Software Application for Colleges of Education Students' Results Processing." Journal of Information Engineering and Applications, Vol. 2, No. 11.

[6] Okonigene, R. E., Ighalo , G. I., and E. Ogbeifun (2008). "Developed Personal Record Software," The Pacific Journal of Science and Technology.

[7] Ukem, E. O. and Onoyom-Ita, E. O. (2011). "A Software Application for the Processing of Students Results," Global Journal of Pure and Applied Sciences. Vol. 17 No. 4.

[8] Ukem, B. O. and Ofoegbu, F. A. (2012). "A Software Application for University Students Results Processing," Journal of Theoretical and Applied Information Technology.

[9] Ngoma, S. (2009). An Exploration of the Effectiveness of SIS in Managing Student Performance. (A final year Dissertation in the School of Post Graduate Studies, Marlboro College, Vermont, USA).

[10] Barrett, S. (1999). Information's Systems: An Exploration of Factors Influencing Effective Use.Journal of Research on Computing in Education, Vol. 32, No. 1, pp. 4-16.

[11] Mohini, .B. and Amar. J. S. (2011). Mode of processing result System. Himachal Pradesh University Journal. pg 123.

[12] Akinmosin, J. (2014). “Automated Students Result Management System Using Oracle’s Database, Forms and Reports", Journal of Information Engineering and Applications. Vol.4, No.1.

[13] Orobor, A. I., (2015), “A Novel Framework for Student Result Computation as a Cloud Computing Service", American Journal of Systems and Software, 2015, Vol. 3, No. 1, pp 13-19.

[14] U.S. Department of Education. (2008). Computer and the Education System. U.S. Department of Education, Washington, D.C. retrieved from: http://www.ed.gov/. 